\title{
Longterm oral cisapride improves interdigestive antroduodenal motility in dyspeptic patients
}

\author{
P A Testoni, F Bagnolo, L Fanti, S Passaretti, A Tittobello
}

\begin{abstract}
We have evaluated the effect of cisapride on interdigestive antroduodenal motility during a prolonged oral therapy in 20 consecutive dyspeptic subjects. Individuals with less than two migrating motor complexes (MMCs) starting from the antral region in $\mathbf{2 4 0}$ minutes and without evidence of upper gastrointestinal tract diseases were randomly treated with either cisapride (10 cases), or placebo (10 cases) for 15 days. Computerised manometry of antroduodenal region was performed for $\mathbf{2 4 0}$ minutes, in basal conditions and on the 15th day of therapy. Symptomatic evaluation of patients was also performed before and after treatment. After cisapride administration, a significant increase in the incidence of antral migrating motor complexes was noticed ( $p=$ 0.022); likewise, the motility index, calculated for phase-2 periods, appeared to be significantly higher both in the antrum and in the duodenum $\quad(\mathbf{p}<0.001)$. Symptomatic improvement was observed in both groups, with a hardly significant $(p=0.049)$ reduction of dyspeptic symptoms severity only but not of frequency in cisapride treated patients $v$ controls. We conclude that longterm oral therapy with cisapride improves interdigestive antroduodenal motor activity.
\end{abstract}

In recent years, motor disorders of the antroduodenal region have been reported among the main factors involved in pathogenesis of dyspeptic syndrome..$^{1-4}$

Previous manometric recording of antroduodenal motor activity ${ }^{1-7}$ and isotopic techniques $^{16}$ showed that delayed gastric emptying and duodenogastric biliary reflux are the most common disorders associated with various and persistent conditions of discomfort of the upper digestive tract, in the absence of organic diseases, that represent the socalled 'functional dyspepsia'.

The prevalence of this common but ill understood entity has been calculated by $\mathrm{Krag}^{8}$ to be $27 \%$ in western populations. Antroduodenal motor disorders - and specifically the delayed gastric emptying - have formed the basis for the use of several prokinetic drugs, stimulating gastroduodenal motor activity, in the treatment of functional, non-ulcer dyspepsia.

Cisapride, a new prokinetic drug devoid of antidopaminergic and direct cholinergic effect, has been recently reported to activate the migrating motor complex (MMC) in the fasting state $^{9}$ and to accelerate gastric emptying ${ }^{10} "$ after iv administration, both in animals and man, as well as to significantly improve dyspeptic symptoms $^{12}$ and gastric emptying ${ }^{13}$ during oral chronic treatment.

At present, however, only few and noncontrolled data are available as to the effectiveness of prolonged oral administration of the drug on the patterns of the antroduodenal interdigestive motility cycle (IDMC). ${ }^{14}$

The aim of this study was, therefore, to assess the effect of prolonged oral treatment with cisapride on the interdigestive motility in patients suffering from persistent dyspeptic symptoms associated with documented motor abnormalities of the antroduodenal region and without evidence of upper gastrointestinal tract organic diseases.

\section{Methods}

\section{SUBJECTS}

Twenty consecutive dyspeptic patients, nine men and 11 women, aged between 22 and 60 years (median age, 39) who at manometric examination of antroduodenal region showed less than two MMCs starting from the antrum in 240 minutes, were included in the study.

All subjects had suffered from dyspepsia for at least six months. Organic diseases of the upper digestive tract were ruled out by means of endoscopy, ultrasonography, abdominal plain $x$ ray film and appropriate biochemical tests; pregnant women and patients with a history of previous abdominal surgery, hepatic diseases with portal hypertension, alcohol consumption
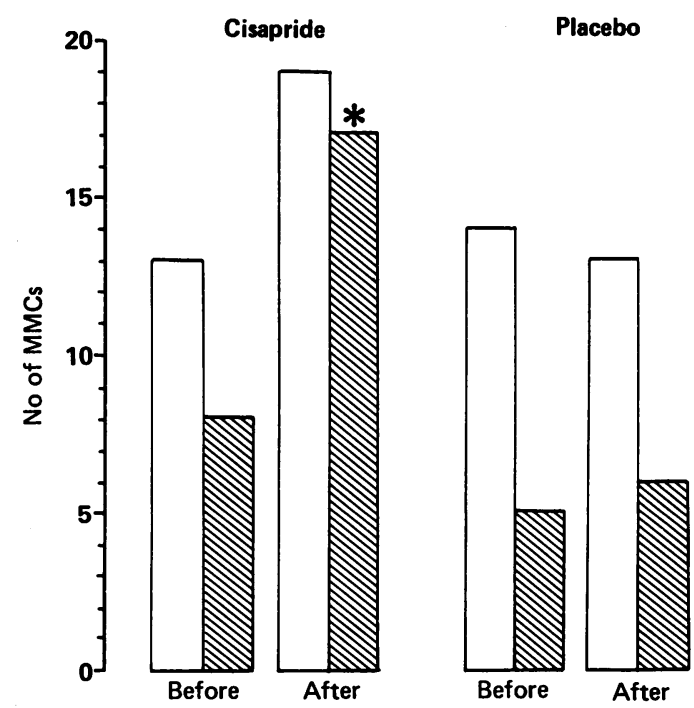

Figure 1: Overall number of MMCs (open bars) and MMCs starting from the antrum (hatched bars), recorded before and after 15-day treatment with oral cisapride and placebo. Postpretreatment comparison performed on single values by Wilcoxon's matched-pairs signed-rank test. ${ }^{*}$ Statistically significant from baseline values, $p=0.022$. 
exceeding $80 \mathrm{~g} /$ day and systemic diseases were also excluded. Informed consent was obtained from each subject admitted to the study.

\section{EXPERIMENTAL DESIGN}

All the patients entered a 15 day single blind randomised trial with either cisapride, $10 \mathrm{mg}$, orally administered four times daily, half an hour before each of the three main meals and at bed time ( 10 cases), or placebo (10 cases).

Manometric recording of interdigestive antroduodenal motor activity and symptom evaluation were performed in basal conditions and on the 15th day of treatment, the last tablet of the drug (cisapride or placebo) being administered in the fasting state half an hour before examination in order to evaluate the antroduodenal motility in steady state conditions. Over the trial duration, the patients were permitted to take only magnesium and aluminium hydroxide antacids, the consumption of which was monitored and compared.

\section{MANOMETRIC RECORDING}

After drugs affecting gastrointestinal motility and gastric secretion had been withdrawn for at least seven days, all patients underwent computerised manometric recording of the antroduodenal region. After an overnight fast, a five lumen polyvinyl chloride probe (external diameter, $0.5 \mathrm{~cm}$ ) with five side holes spaced 5 $\mathrm{cm}$ apart and surface radiopaque markers located in the middle between the third and the fourth hole, was positioned under fluoroscopic control in the proximal part of the duodenum, by locating the radiopaque markers across the pyloric junction. The three upper recording holes were placed in the distal stomach $(12.5$, 7.5 and $2.5 \mathrm{~cm}$ before the pylorus) and the two distal holes in the proximal duodenum $(2.5$ and $7 \cdot 5 \mathrm{~cm}$ after the pyloric ring). The probe position was also verified fluoroscopically at the end of the examination.

The recording catheters were perfused with distilled water, using a pneumohydraulic low compliance pump, and were connected by five Statham P23 ID transducers to a six channel polygraph (OTE Biomedica). Perfusion pressure was 50 kilopascal $(375 \mathrm{mmHg})$ and perfusion rate was $0.5 \mathrm{ml} / \mathrm{min}$. Respiratory excursions were monitored by means of a strain gauge pneumograph fitted around the patients' abdomen. Manometric data were collected and stored on disks for later analysis, by software developed in our centre. Recording of interdigestive motor activity was prolonged over 240 minutes, as suggested by other authors. ${ }^{615-17}$
According to previous reports,,$^{15-20}$ the three different phases of each interdigestive motility cycle (IDMC) were visually identified: phase 1 characterised by motor quiescence, phase 2 by irregular motor activity, and phase $3,-$ that is, the migrating motor complex - by a short burst of rhythmic contractions (activity front).

The following determinants of the interdigestive motility cycle (IDMC) were evaluated: number and site of onset of migrating motor complexes (MMCs); duration of the IDMC; duration of each phase of the IDMC over the recording period. With regard to phase- 2 periods, number and amplitude of phasic contractions were also determined, not including waves $<8 \mathrm{mmHg}$ to avoid erroneous evaluation of respiratory excursions. A motility index was also calculated, for each sequential 10 minute period and for each of the five recording channels, as number of waves $\times$ sum of amplitudes, according to the method described by Malagelada and Stanghellini. ${ }^{4}$ The values thus computed were cumulated over time to obtain a phase- 2 motility index per hour. Finally, phase- 2 tracings were analysed for propagated motor waves - that is, contractions migrating aborally at $1-3 \mathrm{~cm} / \mathrm{sec}$ and recorded consecutively at all the five recording channels.

\section{SYMPTOM SCORING}

The following nine symptoms, heartburn, regurgitation, belching, nausea, vomiting, postprandial fullness, postprandial drowsiness, epigastric pain, and bloating were recorded with regard to frequency $(0=$ symptom absence; $1=$ one to three episodes/week; 2 =four to seven episodes/week; $3=$ more than seven episodes week) and severity $(1=$ mild; $2=$ moderate; $3=$ severe); the evaluation of symptom severity was formulated by the patients themselves, to avoid observer bias. Only subjects presenting at least three symptoms for over six months underwent manometric recording of interdigestive antroduodenal motility, in order to be included in the study.

\section{STATISTICAL ANALYSIS}

As the available data did not show a normal distribution or represented score values, statistical analysis was performed by means of non-parametric tests. After overall data were tested by Friedman's ANOVA, baseline values were confirmed to be comparable by MannWhitney $\mathrm{U}$ test; intraindividual changes (postpretreatment) were evaluated using Wilcoxon's matched-pairs signed-rank test, two-tailed p values were computed.

TABLE I Duration of the single phases of the IDMC over the recording time, number and duration of the IDMCs before and after 15-day treatment with oral cisapride and placebo

\begin{tabular}{lllllll}
\hline & & Phase 1 $($ min $)$ & Phase 2 $($ min $)$ & Phase 3 $($ min $)$ & $\begin{array}{l}\text { IDMCs } \\
(n)\end{array}$ & $\begin{array}{l}\text { Duration of the } \\
\text { IDMC }(\text { min })\end{array}$ \\
\hline Cisapride & Baseline & $134 \cdot 5(102-156)$ & $102 \cdot 5(69-126)$ & $8 \cdot 0(0-15)$ & 4 & $132 \cdot 5(85-162)$ \\
Placebo & Post treatment & $117 \cdot 5(98-151)$ & $109 \cdot 5(60-134)$ & $13 \cdot 5(3-29)$ & 9 & $99 \cdot 0(56-126)$ \\
& Baseline & $113.5(105-143)$ & $115 \cdot 0(91-132)$ & $8 \cdot 5(0-18)$ & 5 & $110 \cdot 0(84-154)$ \\
& Post treatment & $119.0(95-154)$ & $114 \cdot 5(86-129)$ & $7 \cdot 5(0-17)$ & 5 & $136.0(81-168)$ \\
\hline
\end{tabular}

Values are median and range. $\mathrm{IDMC}=$ interdigestive motility cycle. 
TABLE II Antral and duodenal phase-2 motor activity before and after 15 day treatment with oral cisapride and placebo

\begin{tabular}{|c|c|c|c|c|c|}
\hline & & \multicolumn{4}{|c|}{ Phasic contractions } \\
\hline & & \multicolumn{2}{|l|}{$n / h$} & \multicolumn{2}{|c|}{ Mean amplitude $(\mathrm{mmHg})$} \\
\hline & & $\overline{\text { Antrum }}$ & Duodenum & Antrum & Duodenum \\
\hline Cisapride & $\begin{array}{l}\text { Baseline } \\
\text { Post treatment }\end{array}$ & $\begin{array}{l}52 \cdot 0(20-114) \\
87 \cdot 5(56-155)^{\star}\end{array}$ & $\begin{array}{l}94 \cdot 5(48-149) \\
116 \cdot 0(75-189)^{\star}\end{array}$ & $\begin{array}{l}24 \cdot 95(13 \cdot 8-36 \cdot 2) \\
29 \cdot 65(17 \cdot 5-37 \cdot 1) \dagger\end{array}$ & $\begin{array}{l}21 \cdot 10(16 \cdot 1-28 \cdot 5) \\
23 \cdot 50(14 \cdot 9-28 \cdot 1)\end{array}$ \\
\hline Placebo & $\begin{array}{l}\text { Baseline } \\
\text { Post treatment }\end{array}$ & $\begin{array}{l}61 \cdot 0(25-106) \\
67 \cdot 0(35-109)\end{array}$ & $\begin{array}{l}92 \cdot 5(49-137) \\
98 \cdot 0(60-134)\end{array}$ & $\begin{array}{l}23 \cdot 50(14 \cdot 9-32 \cdot 8) \\
22 \cdot 30(15 \cdot 4-31 \cdot 2)\end{array}$ & $\begin{array}{l}20 \cdot 30(15 \cdot 4-29 \cdot 1) \\
20 \cdot 25(15 \cdot 5-27 \cdot 4)\end{array}$ \\
\hline
\end{tabular}

Values are median and range.

Significant at ${ }^{\star} \mathrm{p}<0.001,+\mathrm{p}=0.001$ compared with baseline values

\section{Results}

ANTRODUODENAL MOTOR ACTIVITY

Longterm treatment with oral cisapride appeared to significantly increase the number of MMCs starting from the gastric antrum $(p=$ 0.022 ) and consequently the overall number of activity fronts (Fig 1). In fact, at the admission to the trial and after the treatment with placebo no patient showed more than one antral MMC in 240 minutes, while on the 15 th day of cisapride administration seven out of the 10 patients presented two or even three (one case) MMCs starting from the antrum in 240 minutes.

An increase in the number of complete IDMCs recorded (from the end of an activity front to the end of the successive one) was also observed, even if the small number of data do not allow a statistical evaluation (Table I). No differences were pointed out regarding the duration of the single phases of the IDMC.

Number and amplitude of phase- 2 contractions and phase- 2 motility index were evaluated by comparing the cumulated values of the three antral and of the two duodenal recording channels. The results (Table II) show in the cisapride treated patients a highly significant increase $(\mathrm{p}<0.001)$ of phase- 2 motor waves frequency both in the antrum and in the duodenum; moreover, in the antral region a higher frequency correlated with a corresponding increased amplitude of phasic contractions $(p=0.001)$.

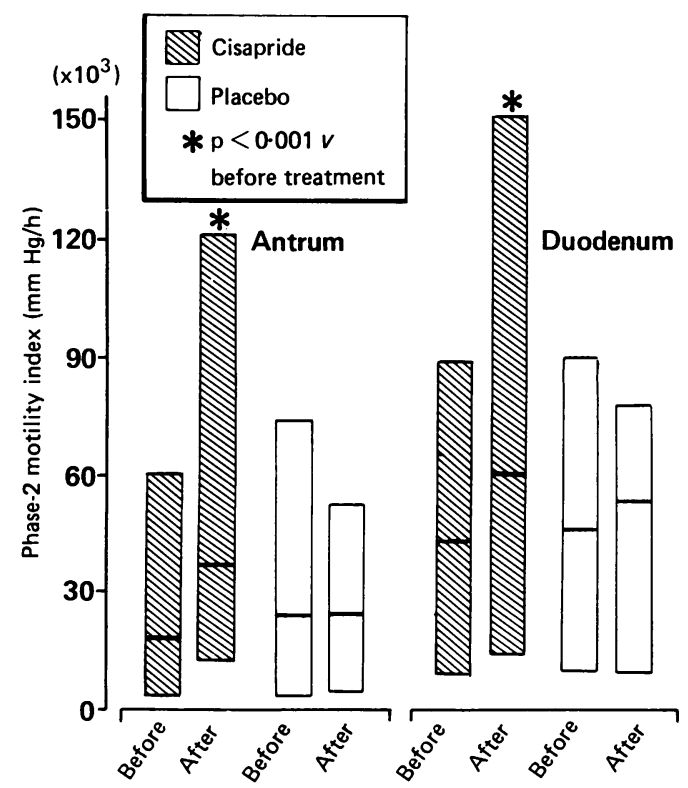

Figure 2: Antral and duodenal phase-2 motility index values (median and range), before and after 15 day treatment with oral cisapride and placebo.
As summarised in Figures 2 and 3, both antral and duodenal phase- 2 motility index values $(p<0.001)$ as well as the number of propagated waves per hour $(p=0.005)$ also appeared significantly higher after cisapride administration, while they did not differ from baseline values after placebo.

\section{SYMPTOM EVALUATION}

In both the groups, no significant variation was detected in the number of symptoms which each patient complained of before and after the treatment. Symptom scores for frequency and severity of all the patients in basal conditions and during the 15 day treatment with oral cisapride or placebo are reported in Table III.

In comparison with pretrial values both cisapride and placebo significantly reduced overall symptoms frequency and severity, with cisapride superior to placebo $(p=0.049)$ only in improving the severity of dyspeptic symptoms. As to discrete symptoms, no important variation was noticed in the two groups. No side effects were reported by the patients or detected by the physicians. Finally, no differences were observed between the two groups of treatment regarding magnesium and aluminium antacids consumption.

\section{Discussion}

Functional dyspepsia is a common event characterised by persistent or episodic sympıoms

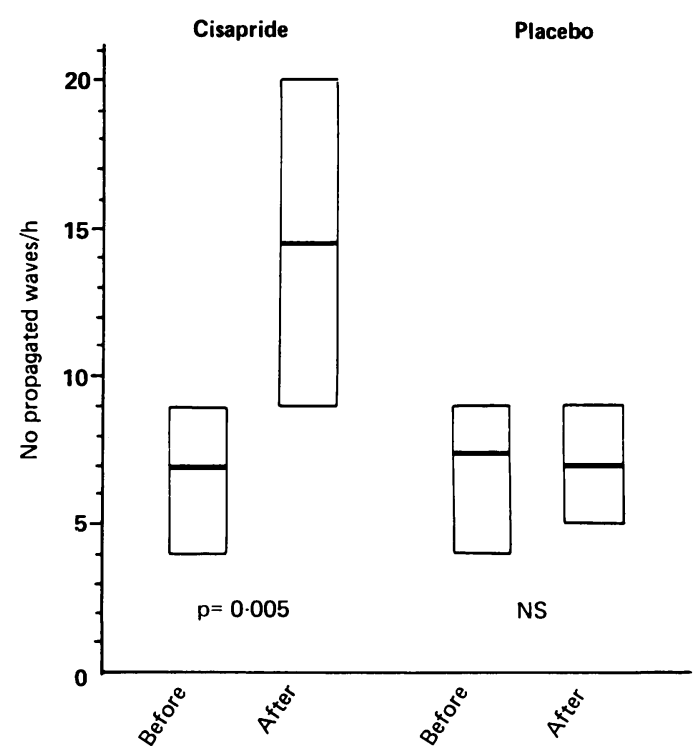

Figure 3: Number of propagated motor waves per hour (median and range), before and after 15 day treatment with oral cisapride and placebo. 
TABLE III Effect of 15-day treatment with oral cisapride or placebo on frequency and severity scores (median; extremes) of discrete and overall symptoms

\begin{tabular}{|c|c|c|c|c|c|c|c|c|}
\hline & \multicolumn{4}{|l|}{ Frequency } & \multicolumn{4}{|l|}{ Severity } \\
\hline & \multicolumn{2}{|l|}{ Cisapride } & \multicolumn{2}{|l|}{ Placebo } & \multicolumn{2}{|l|}{ Cisapride } & \multicolumn{2}{|l|}{ Placebo } \\
\hline & pre & post & pre & post & pre & post & pre & post \\
\hline $\begin{array}{l}\text { Heartburn } \\
\text { Regurgitation } \\
\text { Belching } \\
\text { Nausea } \\
\text { Vomiting } \\
\text { Postprandial fullness } \\
\text { Postprandial drowsiness } \\
\text { Epigastric pain } \\
\text { Bloating }\end{array}$ & $\begin{array}{l}1 ; 1-3(4) \\
3 ; 1-3(8) \\
3 ; 3-3(2) \\
1 \cdot 5 ; 1-2(4) \\
1 \cdot 5 ; 1-2(2) \\
3 ; 2-3(7) \\
3 ; 3-3(10) \\
2 ; 2-2(1) \\
2 \cdot 5 ; 1-3(4)\end{array}$ & $\begin{array}{l}0 ; 0-2(1) \\
1 ; 0-3(5) \\
2 ; 2-2(2) \\
1 ; 0-1(3) \\
0 ; 0-0(0) \\
3 ; 2-3(7) \\
3 ; 0-3(9) \\
0 ; 0-0(0) \\
2 ; 1-3(4)\end{array}$ & $\begin{array}{l}2 ; 2-2(2) \\
3 ; 3-3(5) \\
3 ; 3-3(5) \\
2 ; 1-3(6) \\
1 ; 1-1(2) \\
3 ; 3-3(8) \\
3 ; 3-3(9) \\
3 ; 3-3(1) \\
3 ; 0-3(5)\end{array}$ & $\begin{array}{l}0 \cdot 5 ; 0-1(1) \\
3 ; 2-3(5) \\
2 ; 2-3(6) \\
1 ; 1-2(6) \\
0 ; 0-0(0) \\
3 ; 3-3(8) \\
3 ; 3-3(9) \\
2 ; 2-2(1) \\
2 \cdot 5 ; 2-3(6)\end{array}$ & $\begin{array}{l}1 ; 1-2(4) \\
2 ; 1-3(8) \\
3 ; 3-3(2) \\
2 \cdot 5 ; 2-3(4) \\
3 ; 3-3(2) \\
3 ; 2-3(7) \\
3 ; 2-3(10) \\
3 ; 3-3(1) \\
3 ; 3-3(4)\end{array}$ & $\begin{array}{l}0 ; 0-1(1) \\
1 ; 0-2(5) \\
2 ; 2-2(2) \\
1 ; 1-3(3) \\
0 ; 0-0(0) \\
2 ; 1-3(7) \\
2 ; 0-3(9) \\
0 ; 0-0(0) \\
3 ; 3-3(4)\end{array}$ & $\begin{array}{l}2 \cdot 5 ; 2-3(2) \\
2 ; 1-2(5) \\
2 ; 1-3(5) \\
3 ; 1-3(6) \\
2 ; 2-2(2) \\
3 ; 2-3(8) \\
3 ; 2-3(9) \\
3 ; 3-3(1) \\
2 \cdot 5 ; 0-3(5)\end{array}$ & $\begin{array}{l}1 \cdot 5 ; 0-3(1) \\
2 ; 1-2(5) \\
1 ; 1-3(5) \\
2 ; 1-3(6) \\
0 ; 0-0(0) \\
3 ; 2-3(8) \\
2 ; 2-3(9) \\
1 ; 1-1(1) \\
3 ; 1-3(6)\end{array}$ \\
\hline Overall symptoms & $10 \cdot 5 ; 7-16$ & $6.5 ; 1-12^{\star}$ & $\begin{array}{c}12 ; 8-17 \\
\text { ns }\end{array}$ & $10 ; 8-15^{\star}$ & $10 \cdot 5 ; 8-16$ & $7 ; 1-11 \dagger$ & $\begin{array}{c}11 ; 7-16 \\
p=0.049\end{array}$ & $9 \cdot 5 ; 7-12^{\star}$ \\
\hline
\end{tabular}

$(\mathbf{n})=$ number of patients presenting the symptom.

Significant at ${ }^{\star} \mathrm{p}=0.022, \mathrm{t} \mathrm{p}=0.014$ compared with baseline values

related to the upper digestive tract in the absence of organic diseases, occurring both in the fasting state and in the postprandial period. Previous studies suggest that major dyspeptic complaints, as nausea, bile vomiting, heartburn and regurgitation (occurring in the fasting state) or postprandial fullness and drowsiness or bloating (in the fed state) are likely to be dependent on motor abnormalities of the antroduodenal region, well documented by manometric recordings and isotopic techniques. ${ }^{1-4}$ In fact, the prolonged duration of the interdigestive motility cycle associated with abnormalities in the frequency, onset and propagation of the migrating motor complex, has been shown to be related on the one hand to increased duodenogastric bile reflux, with possible impairment of the clearing capacity of the distal stomach and subsequent bile stasis in the fasting state, ${ }^{7821}$ and on the other hand to delayed gastric emptying. The reduced incidence or the absence of MMCs in the antrum, regardless to any other parameter, particularly seems 'per se' to play a major role in the dyspeptic syndrome. ${ }^{46}$

The significance of these abnormalities of the phase 3 of the IDMC in the antral region is at present unknown; it is also difficult to define a standard motility pattern in man, as a great variability in the incidence of migrating motor complexes has been reported both in healthy individuals and in dyspeptic subjects. Moreover, the multilumen probe inserted across the pylorus in the duodenum might be responsible for possible changes of antroduodenal motility, even if there is evidence that the catheter does not significantly affect the motility pattern. ${ }^{21} 22$

There is, however, general agreement that most normal subjects show at least two consecutive MMCs during a recording period of 240 minutes, ${ }^{6} 1523$ although in some cases the absence of MMCs has been described. ${ }^{21}$ In the last years several reports have shown that cisapride is effective in the treatment of functional, nonulcer dyspepsia, by improving both the antroduodenal motility pattern and the subjective symptoms. ${ }^{10-13}$ Manometric recordings of the upper digestive tract motility have documented that iv infusion or single oral administration of cisapride during the phase 1 of the interdigestive motility cycle (IDMC) induces a prolonged and highly propagative phase- 2 like jejunal motor activity in fasting humans ${ }^{162+}$ and improves the antroduodenal coordination..$^{25}$ Moreover, isotopic studies have shown that iv administration of the drug significantly accelerates gastric emptying of solids in dyspeptic subjects ${ }^{1011}$ and increases antral contraction amplitude in subjects with primary anorexia nervosa."

In a preliminary non-controlled study after oral prolonged administration, cisapride seems to significantly accelerate gastric emptying ${ }^{13}$ and improve the interdigestive motility cyçe. ${ }^{14}$ On the other hand, no objective data are at present available on the possible effectiveness of an oral prolonged treatment with cisapride in normalising the frequency of antral migrating motor complexes and in modifying other parameters of interdigestive phasic activity in patients suffering from non-ulcer dyspepsia.

Cisapride, orally administered for 15 days, appeared in our single blind placebo controlled study to be significantly effective in improving interdigestive antroduodenal motility. Cisapride particularly promoted a significant increase of MMCs starting from the gastric antrum; in fact, after the treatment with the drug seven of the 10 patients ( $v$ no case in the placebo group) showed two consecutive antral MMCs during the 240 minute recording period and they did not present any more the motor abnormalities required for inclusion in the study. Nevertheless, as regards dyspeptic symptoms, a similar improvement was observed in both the groups of treatment (cisapride was significantly more effective than placebo only in reducing symptom severity), without any correlation with antroduodenal motility pattern. This is not surprising considering on the one hand the role played by the placebo effect on the subjective evaluation of symptoms in dyspeptic patients and on the other hand the relatively short period of treatment. Also the fact that symptoms improved with the placebo despite any improvement in interdigestive antroduodenal motor activity suggest that motility disorders are not the only factor involved in the genesis of dyspepsia.

Partially in agreement with other studies performed with single doses of cisapride, ${ }^{11} 1624$ in our series the drug was shown to induce a phase2 motor activity characterised by a significantly higher number and amplitude (this latter only in the antrum) of phasic contractions and by significantly more aborally propagated waves; on the other hand, we observed neither a pro- 
longation of the time spent in the phase 2 of the IDMC, nor an increased interval between consecutive MMCs.

The improvement of the antroduodenal coordination, expressed by the increase of propagated waves, and the higher pressure activity recorded in the antrum but not in the duodenum, could be responsible for the acceleration of gastric emptying as pointed out by other authors, ${ }^{10113}$ after cisapride administration.

Further investigation would be probably required to verify these findings during the postprandial period also, by means of a 24 hour computerised manometric recording, thus comparing manometric and isotopic results.

1 Rock E, Malmud L, Fisher RS. Motor disorders of the stomach. Med Clin North Am 1981; 65: 1269-89.

2 Vantrappen GR, Janssens J. Intestinal motility disorders. Dig Dis Sci 1984; 29: 458-62.

3 Fisher RS. Gastroduodenal motility disturbances in man. Scand f Gastroenterol 1985; 20: (Suppl 109): 59-68.

4 Malagelada JR, Stanghellini V. Manometric evaluation of functional upper gut symptoms. Gastroenterology 1985; 88 1223-31.

5 Miranda $M$, Defilippi C, Valenzuela JE. Abnormalities of interdigestive motility complex and increased duodenogastric reflux in gastric ulcer patients. Dig Dis $S c i 1985 ; 30$

6 Labò G, Bortolotti M, Vezzadini P, Bonora G, Bersani G. Interdigestive gastroduodenal motility and serum motilin levels in patients with idiopathic delay in gastric emptying. Gastroenterology 1986; 90: 20-6.

7 Testoni PA, Fanti L, Passaretti S, Masci E, Guslandi M, Tittobello A. Interdigestive motility pattern in subjects with Tittobello A. Interdigestive motility pattern in subjects with duodenogas.

$8 \mathrm{Krag} \mathrm{E}$. Non-ulcer dyspepsia introduction: epidemiological data. Scand f Gastroenterol 1982; 17: (Suppl 79): 6-8

9 Lee KY, Chey WY, You CH, Shah AN, Hamilton D. Effect of cisapride on the motility of gut in dogs and colonic transi time in dogs and humans. [Abstract.] Gastroenterology 1984 86: 1157.

10 Jian R, Ducrot F, Piedeloup C, Mary JY, Najean Y, Bernier $\mathrm{JJ}$. Measurement of gastric emptying in dyspeptic patients: effect of a new gastrokinetic agent (cisapride). Gut 1985; 26: 352-8.

11 Stacher G, Bergmann H, Wiesnagrotzki S, et al. Intravenous cisapride accelerates delayed gastric emptying and increases antral contraction amplitude in patients with primary anorexia nervosa. Gastroenterologv 1987; 92: 1000-6.

12 Rösch W. Cisapride in non-ulcer dyspepsia. Results of a placebo-controlled trial. Scand $\mathcal{F}$ Gastroenterol 1987; 22 $161-4$

13 Corinaldesi R, Stanghellini V, Raiti C, Rea E, Salgemini R, Barbara L. Effects of chronic administration of cisapride on gastric emptying of a solid meal and on dyspeptic symptoms in patients with idiopathic gastroparesis. Gut 1987; 28: 3005 .

14 Testoni PA, Bagnolo F, Fanti L, Passaretti S, Tittobello A. Effect of long-term oral therapy with cisapride on the interdigestive antro-duodenal motility pattern in dyspeptic subjects. Curr Ther Res 1988; 43: 1118-26.

15 Vantrappen G, Janssens J, Hellemans J, Ghoos Y. The interdigestive motor complex of normal subjects and patients with bacterial overgrowth of the small intestine. patients with bacterial overgrow

16 Stacher G, Steinringer H, Schneider C, Winklehener S Mittlebach G, Gaupmann G. Effects of cisapride of jejunal motor activity in fasting healthy humans. Gastroenterology 1986; 90: $1210-6$

17 Dooley CP, El Newihi HM, Zeidler A, Valenzuela JE. Abnormalities of migrating motor complex in diabetics with autonomic neuropathy and diarrhea. Scand 7 Gastroenterol 1988; 23: 217-23.

18 Code CF, Schlegel JF. The gastrointestinal interdigestive housekeeper: motor correlates of the interdigestive myoelectric complex of the dog. In: Daniel EE, ed myoelectric complex of the dog. In: Daniel EE, ed.
Proceedings of the Fourth International Symposium on Proceedings of the Fourth International Symposium on gastrointe

19 Wingate DL. Backwards and forwards with the migrating motor complex. Dig Dis Sci 1981; 26: 641-66.

20 Rees WDW, Malagelada JR, Miller LJ, Go VLM. Human interdigestive and postprandial gastrointestinal motor and gastrointestinal hormone patterns. Dig Dis $S_{c i} 1982 ; 27$ : $321-9$

21 Keane FB, Di Magno EP, Malagelada JR. Duodenogastric reflux in humans: its relationship to fasting antro-duodenal motility and gastric, pancreatic and biliary secretion. Gastroenterology, 1981;81: 726-31.

22 Mueller-Lissner SA. Schottenmann G, Schenker G, et al. Duodenogastric reflux in the fasting dog: role of pylorus and duodenal motility. Am f Physiol 1981; 241: 159-62.

23 Larsen $S$, Osnes $M$. The unstimulated duodenal pressure activity in healthy humans. Scand $\mathcal{F}$ Gastroenterol 1987; 22 (Suppl 131): 1-36.

24 Stacher G, Gaupmann G, Mittelbach G, Schneider C, Steinringer $\mathrm{H}$, Langer B. Effects of oral cisapride on interdigestive jejunal motor activity, psychomotor function, and side-effect profile in healthy man. Dig Dis Sci 1987; 32. 1223-30.

25 Akkermans LMA, Roelofs JMM, de Ridder JM, et al. Computerized analysis of electrical and mechanical coordination in the antroduodenal region. [Abstract.] Dig Dis Sci 1985; 30: 756 . 